\title{
A performance measurement system to quantify the contribution of social media: new requirements for metrics and methods
}

\author{
Deborah Agostino, Yulia Sidorova \\ Department of Management Economics and Industrial Engineering, Politecnico di Milano
}

\begin{abstract}
Purpose - This paper focuses on measuring the contribution generated by social media when used for business purposes, distinguishing between metrics and methods for data collection and data analysis. Organizations worldwide have widely endorsed social media, but available studies on the contribution generated by these technologies for organizations are fragmented. A Performance Measurement System (PMS) framework to monitor social media is theoretically derived, highlighting the methods for data collection and data analysis and metrics to quantify social media impacts in terms of financials, network structure, interactions, conversations and users’ opinion.

Design/Methodology/Approach - This is a qualitative research based on a literature review of papers in management, information technology, marketing and public relations.

Findings - A PMS framework to quantify the contribution of social media is theoretically derived, distinguishing between metrics and methods. PMS metrics support the measurement of the financial and relational impact of social media, as well as the impact of social media conversations and users' opinions. PMS methods comprise different approaches for data collection and data analysis that range from manual to automated data collection and from content to sentiment analysis techniques.

Originality/Value -The PMS framework contributes to the academic literature by integrating a unique model of the available approaches for social media measurement that can serve as a basis for future research directions. The framework also supports practitioners that face necessity to quantify financial and relational contributions of social media as well as the contribution of social media conversation and users' opinion.
\end{abstract}

Keywords Performance Measures, Social media, Metrics, Methods

Paper Type Research paper 


\section{INTRODUCTION}

Social media, which broadly refers to online tools based on social interactions and user generated content (Kaplan and Haenlein, 2010), is characterized by three main features that distinguish these technologies from other web-based tools: real time communication, many-to-many interactions and user-generated content (Peters et al., 2013). Indeed, social media users have the possibility to interact in real time with peers in many-to-many networks by posting their comments, photos or videos in real time. These features have boosted social media diffusion worldwide at both individual and organizational levels. At the individual level, over 52\% of Americans regularly use several social media platforms, with over 65\% of population that has at least one account on social media (Duggan et al., 2015).

At the organizational level, social media has become one of the main tools for communication, promotion, retention and penetration (e.g., Hanna et al., 2011; McCaughey et al., 2014; Khan et al., 2014). Organizations of different natures and of different sizes are adopting social media for a variety of purposes (e.g., Waters, 2009; Michaelidou et al., 2011). For example, in April 2013, the U.S. Securities and Exchange Commission issued a report that permit companies to "use social media outlets like Facebook and Twitter to announce key information in compliance with Regulation Fair Disclosure” (SEC, 2013).

Together with the widespread adoption of these social technologies, practitioners and academics have recognized the need for organizations to quantify the contribution of social media activities used for business purposes both with reference to financial contribution and value generated by social media data from users' conversations.

Looking at the practitioners' needs, it has been acknowledged that "executives in nearly every industry are looking for ways to reap value from analytics” (Kim et al., 2014), hence underlining the importance to quantify the contribution generated by social media conversations. The importance to quantify the social media contributions is also recognized in several academic disciplines, although with different nuances. The marketing literature acknowledged that "SNS [social networking site] need to be evaluated for their effectiveness” (Michaelidou et al., 2011: 1155), stressing the importance for companies to evaluate the financial contribution of social media activities (Hanna et al., 2011). The public relations literature instead has mainly focused on social media contributions in terms of interactions and relationships that occur on these social tools with studies underlying the importance to quantify the ability to interact effectively with customers through social channels (Waters, 2009). Finally, IT (Information Technology) scholars who are interested in the development of new 
techniques to download and analyse social media data have mainly pointed the attention on methods to analyse social media data (e.g., Chen et al., 2012).

The reasons behind the importance to quantify the contribution of social media activities lie in the possibility to exploit social media data to support organizations' purposes and informal learning (Raybourn, 2014). Indeed, social media data are deemed precious for companies to assess performance (Senior, 2015) and to support business growth and profitability (El-Sayed and Westrup, 2011).

Starting from this premise, some studies have developed with the aim to explore how to measure social media contributions, but these studies focus on specific indicators or on specific methods to download and analyse social media data (e.g., Bravo-Marquez et al., 2014; Yan et al., 2014), giving rise to a fragmented landscape about which aspects of social media should be measured and how they should be measured. An overarching view about social media measurement is missing. By framing our investigation around the notion of a Performance Measurement System (PMS), this paper aims at understanding the available metrics and methods to quantify the contribution generated by social media activities, considering both financial and non-financial impacts, such as interactivity, conversation, or users' opinions. Specifically, the following research questions are addressed: What are the available metrics to measure the contribution of social media activities? What are the required methods to accomplish these metrics? To address these questions, we conducted a literature review on management, information technology (IT), marketing and public relations journals. The main result of this paper is the development of an overarching PMS framework for social media that provides a comprehensive view of social media measurement.

\section{PMS: METRICS AND METHODS}

To explore how to measure social media contributions, we framed our analysis around the notion of a Performance Measurement System (PMS), which refers to both financial and non-financial indicators (Neely et al., 2001; Sihm and Koh, 2001). It represents a valuable and longstanding tool to plan and understand how activities are performed by individuals or organizations (Choong, 2013). PMSs have been widely implemented in private, nonprofit and public organizations to monitor organizational learning and support decision making, motivate individuals and provide external accountability (e.g., Meekings and Briault, 2013; Canonico et al., 2015). A wide variety of activities are measured and controlled through PMSs with social media representing one of the last challenges. A PMS is constituted by two main components: metrics and methods. Metrics represents a set of indicators that facilitate the quantification of an object of control, which can be an organization, a unit, an individual, a product or a service. In our specific setting, the object of control is represented 
by social media or its constitutive components, and metrics includes indicators that facilitate the quantification of social media activities.

Methods, instead, refers to the approaches required to compute the abovementioned metrics. With reference to social media, methods includes approaches to download and analyse data. Following this conceptualization of a PMS as a system constituted by metrics and methods, we analyse and systematize the existing literature on social media measurement. The next section describes the research design adopted.

\section{METHODOLOGY}

This is a conceptual study that adopted a qualitative methodology based on a literature review to build an overarching view on social media measurement framed along the notion of a PMS. We performed this review following three main steps. The first step consisted of searching academic articles using a combination of keywords:

- Social media

- Performance measure

- Indicator

- Metric

- Facebook, Twitter, YouTube, LinkedIn

- Data analysis, data collection.

Initially, the search engine Scopus was adopted. We have chosen information technology, marketing, public relations and management outlets to find studies covering relevant arguments defined by the key words. The initial search resulted in a total of 190 papers. We have complemented this search and added 23 papers with a snowball approach to review citations of the retrieved papers to identify further appropriate material not emerged with the keywords search.

As a second step, we manually read the abstract of the retrieved papers to select the relevant studies only. We adopted two criteria for inclusion. First, given that the purpose of our research to identify the available metrics and methods for social media measurement, a clear reference to metrics or methods for analysis had to be included in the paper. Second, papers had to be published in refereed journals, conference proceedings or published books to increase the quality of the material. This refinement led to the selection of 51 papers. The third step consisted of the development of an overarching PMS framework for social media measurement, which is based on the constitutive components of a PMS (metrics and methods). To achieve this, we did an in-depth reading of the selected papers. We charted the content of the retrieved papers along the two dimensions of PMS metrics and methods; this step further distinguished between data collection and data analysis. This 
organization of the papers provided a summary of the current state of the literature about PMS and social media, which supported the definition of a PMS framework for social media analysis as presented in the next section.

\section{A PMS FRAMEWORK IN THE SOCIAL MEDIA ERA}

This section proposes a PMS framework to quantify the contribution of social media activities starting from results derived from the literature review. The proposed framework is composed of two main elements:

- Metrics refers to indicators used to quantify social media contributions;

- Methods refers to the approaches to retrieve and analyse data to feed the PMS. They comprise both data collection and data analysis methodologies.

The starting point of the framework is the specific type of social media contributions that need to be measured. This contribution can refer to different aspects: financial, network structure, interactions, content of social media conversations and users' opinions. Depending upon which types of contribution have to be measured, the metrics and methods are different (Table 1).

< Insert Table 1 almost here $>$

\subsection{PMS metrics}

PMS metrics can vary from financial indicators, network structure indicators, interactions indicators, content indicators and sentiment indicators depending on the type of social media contributions that need to be assessed (see Annex 1 for the full metric list).

Financial indicators provide a synthetic evaluation of the financial contribution of social media in terms of the profitability of the social media investment. They are derived by indicators traditionally used to evaluate organizations; the metric is the same, but the object of control has shifted from the organization to social media as a whole. A foremost indicator is represented by social media ROI (Fisher, 2009; Powell et al., 2011; Romero, 2011; Kaske et al, 2012; Crumpton, 2014; Jobs and Gilfoil, 2014). The traditional formula adopted by companies to evaluate the Return On Investment (ROI) is suggested for the quantification of the social media ROI, providing a synthetic evaluation about the ability of the organization using social media. The social media ROI has more than 14 different definitions (Crumpton, 2014), and its calculation has been acknowledged as a challenge both for business and non-profit organizations (Fisher, 2009; Romero, 2011, Jobs and Gilfoil, 2014). The social media ROI could be measured for specific campaigns or actions on social media (Romero, 2011, Jobs and Gilfoil, 2014) where the costs and benefits could be easily defined and calculated. In 
this case, this indicator lacks the ability to provide an overall picture. In this respect, it has been said that "ROI is missing the point of social media" (Fisher, 2009, p. 194), mainly because it provides a partial view on social media contributions because it is unable to measure community reactions and interactions with the company (Kaske et al., 2012, Crumpton, 2014; Jobs and Gilfoil, 2014). Therefore, a large number of non-financial indicators emerged to account for specific characteristics of social media (network structure, interactivity, content, and sentiment) to support managerial activities.

Network structure indicators support the evaluation of the contribution generated by the network of social media users. Accordingly, the control object is represented by network structure and its relationships with indicators that allow for quantification of the network structure. These indicators are mainly derived from network theory, starting from the recognition that every network is characterized by a set of nodes connected by ties. They comprise multiplexity, centrality, density, and closeness (Coulter and Roggeveen, 2012; Ellison and Boyd, 2013; Kane et al., 2014), and allow, for example, for the identification of the influencer, intended as the node in the network, with a predominant role to influence the others (Li et al., 2014; Bernabé-Moreno et al., 2015).

Interactions indicators support the quantification of network interactions with the aim to measure the activity of the social media users. They are mainly discussed in marketing and public relations literature and comprise awareness, engagement, word of mouth, and virality. Awareness quantifies the ability of an organization to broadcast information to users through social media (Hoffman and Fodor, 2010; Agostino, 2013). Engagement measures the ability of an organization to establish dialogue and interactions with social media users (Hoffman and Fodor, 2010; Agostino, 2013; Bonsón and Ratkai, 2013) and is based on the quantification of responses to social media posts. Word of mouth (Hoffman and Fodor, 2010) evaluates the ability of social media users to communicate their opinion to other users, hence contributing to the popularity of a post. Virality (Bonsón and Ratkai, 2013) is a proxy for the intensity of propagation of a message posted on social media. The computation of these indicators requires the collection of specific social media data, such as the number of "Likes", "Fans" or "Shares” for Facebook or the number of "tweets", "retweets" or “replies” for Twitter. Furthermore, metrics per each of these indicators change according to the specific social media. For example, engagement is calculated by counting the number of replies on Twitter, the number of comments on Facebook and the number of subscribers on YouTube (Hoffman and Fodor, 2010; Agostino, 2013).

Content indicators aim to evaluate the contribution of social media conversations by quantifying the topics of social media dialogues. Studies in this field identify categories to classify images, themes, features, links, exchanges and languages that occur in social media conversations (Herring, 2010). 
For example, Waters et al. (2009) identified 30 items to classify Twitter posts of nonprofit organizations. Within the journalism field, two indicators were developed: relevance, which quantifies the importance of a given word, and uniqueness, which quantifies the occurrence of a word or sentence (Diakopoulos et al., 2010).

Finally, sentiment indicators quantify the contribution of users' opinions on social media. These indicators, mainly discussed in IT literature, quantify the sentiment (positive, neutral or negative) associated with social media conversations. A variety of measures can be found to quantify the sentiment of conversations, and the debate on the most appropriate metric is still open. Asur and Huberman (2010) proposed a subjectivity and polarity ratio by focusing specifically on Twitter. The former assesses the level of subjectivity of tweets by calculating the ratio between the number of positive and negative tweets with respect to the neutral ones. The latter quantifies whether the sentiment is mainly positive or negative by computing the ratio between tweets with positive sentiments and those with negative ones. Starting from the importance of "assessing opinions, evaluations, speculations, and emotions in free text” (Zhang et al., 2012: 3), a set of sentiment divergence metrics have been proposed by identifying formulas to quantify the rating (importance) and the review (to reflect consumers’ opinions) of each comment on social media.

\subsection{PMS methods}

The PMS component of methods refers to the required approaches to compute social media data, and it is further distinguished by data collection and data analysis.

\section{Data collection}

Data collection refers to the available approaches to download social media data. While financial and network structure indicators do not require specific approaches to collect data, the computation of interactions, content and sentiment indicators demands ad hoc approaches for data collection. From the literature, three main approaches for social media data collection have been identified.

The first approach is default data collection (van Dam and van de Velden, 2015; Ngai et al., 2015). It consists of accessing already given information from social media, usually offered for free by the social media provider. For example, Twitter analytics (https://analytics.twitter.com) or Facebook Insights (Facebook statistics) provide companies with the possibility to access and download some information about their own social page or their popularity over the time.

The second approach concerns manual data collection, intended as the physical collection of unstructured texts and other social media data, such as numbers of "Followers," "Posts," "Shares" or “Likes”, from social media platforms. Some studies (e.g., Snead, 2013; Sebate et al., 2014) rely on 
manual data collection to gather information about the interactivity level of a social page. This approach implies a time consuming process (Farrugia et al., 2012), which is feasible for social media with a low number of users or for specific data collection purposes.

The third approach, automated data collection (Atkinson et al., 2015), relies on an automated procedure to systematically gather social media data. The most common methodology to retrieve social media data is based on an automated program called 'web crawler', which retrieves web pages and their content for further use (Pinkerton, 1994). These crawlers have been developed since the 1990s (e.g., Pinkerton, 1994), but algorithms to query the web have recently evolved to address the scaling problem of today's big data. The approaches for crawling social media data can be classified into two main categories: crawlers that rely on ad hoc API (Application Programming Interface) and crawlers that rely on HTML (Hyper Text Markup Language) scraping (Ferrara et al., 2014), which differ based on how the query on the social media is set. The first approach is offered by the social media platform, such as Twitter API or Google Social Graph API (e.g., Kwak et al., 2010; Choi et al., 2012). This approach guarantees high performance, but the quantity of downloadable data is constrained by the policies defined by the social media platform. For example, the Twitter API allows only 150 requests per hour and a maximum download of 1500 tweets per query.

The second approach still allows for the downloading of social media data but without relying on any service offered by the social media provider (Marres and Weltevrede, 2013). On the contrary, a rule is developed to autonomously query the web page. With respect to the approach based on API, HTML scraping does not have any limitation on the quantity of information that can be extracted, but its requests can be blocked by the social media provider.

\section{Data analysis}

Data analysis refers to approaches to transform the collected unstructured data from social media into usable data to compute social media indicators. Traditional statistic techniques, such as correlation, regression or cluster analysis (Dzvapatsva et al., 2014), and network theory approaches that identify the most influential figures or strong and weak interconnections (e.g., Li et al., 2014) have been complemented by novel data analysis methods. These novel methods are extensions of longstanding data mining techniques (Ngai et al., 2009) and comprise content and sentiment analysis that supports the computation of content and sentiment indicators, respectively.

Content analysis is a technique that allows for the coding of text, mainly by counting word frequency to reduce large volumes of data (Stemler, 2001). This technique existed long before the diffusion of 
social media (e.g., Krippendorff, 1980), but novel approaches are emerging to address the huge amount of social media data: Natural Language Processing and Semantic Web Approaches.

The former is "a mechanism to extract useful information from the conversational data from the social media channels” (Bhardwaj et al., 2014: 106). This approach has "the general objective to create algorithms capable of 'understanding' natural language through techniques ranging from the simple manipulation of strings to the automatic processing of natural language inquiries” (Larson and Watson, 2013: 3). Several studies mine social media data by adopting this algorithm (e.g., Bunescu and Mooney 2007; Buckley et al., 2014).

The latter extracts meaning from social media data by adopting "labels (via marking up, tagging, or annotating) that follow an agreed-upon reference model, be it a common nomenclature, dictionary, taxonomy, folksonomy, or ontology that represents a specific domain model” (Sheth and Nagarajan, 2009; Shet et al., 2010). The difference between the two methodologies is the following: Natural Language Processing approaches look for similarities between words, and Semantic Web Approaches search for the specific match between two sets of words (Sobkowicz et al., 2012). Whatever the method, a further step in content analysis is to complement these techniques with further social media features, such as the geolocalization (Bernabé-Moreno et al., 2015), which delivers content indicators per each specific place.

Sentiment analysis supports the computation of sentiment indicators through the identification of opinions contained in social media data (Thelwall et al., 2010; Nguyen et al., 2014). It is usually performed by two consecutive tasks: identification of the opinion and identification of its polarity, either positive, negative or neutral (Pang and Lee, 2008). Automatic techniques to classify the polarity of a text include Supervised Techniques, Unsupervised Methods and Semi-Supervised Methods. Supervised techniques require a manual phase to train the system to identify the polarity of a predefined set of words, and then it will continue automatically to assign polarity to the text (Neri et al., 2010; Bravo-Marquez et al., 2014). Hence, the system learns from the initial manual tagging phase. Unsupervised Techniques do not require any prior training phase; instead, they require a predefined lexicon that allows for the scoring of text as positive, negative or neutral (e.g., Paltoglou and Thelwall, 2012; Hu et al., 2013; Xianghua et al., 2013). Among these two techniques, SemiSupervised Methods "address the polarity classification by expanding an initial set of sentiment words through synonyms and antonyms retrieved by thesauruses” (Fersini et al., 2014: 27).

The main limit of these techniques is the language, given that they classify the sentiment of a text in one language only. More recent studies have developed sentiment analysis approaches that exploit multiple languages simultaneously (e.g., Wan, 2011; Yan et al., 2014), which are particularly relevant for social media given the coexistence of several languages in the same platform. 


\section{DISCUSSION AND CONCLUSION}

This study develops a PMS framework to quantify the contribution of social media activities by distinguishing between two main dimensions: metrics and methods. The metric dimension comprises different types of indicators that support the quantification of social media contributions in terms of financials, network structure, interactions, conversations and users' opinion. The method dimension refers to approaches for data collection (moving from default, manual, and automated) and data analysis (including traditional statistical techniques, as well as content and sentiment analysis). The rationale behind this investigation is that "categorizing big data, assessing its quality, and identifying its impact is radically new in social sciences, especially in management and organizational research” (George et al, 2014 p. 324)

The developed PMS framework provides implications for both academics and practitioners.

From an academic perspective, the PMS framework answers the question of Khan et al. (2014) by illuminating the relationships between social media, methods and metrics and individualizing the contribution from social media activities within PMS. The framework highlights two main challenges for social media measurement, which can serve as an agenda to guide future research. The first challenge is connected to social media content and sentiment indicators. Unlike traditional indicators that are usually based on numbers (Neely et al., 2001; Sihm and Koh, 2001), social media indicators are moving towards more text-based and subjective measures to quantify discussions and users' opinions by introducing the importance of quantifying words rather than numbers. This insight can drive further research on the conceptualization of the relevant dimensions for a PMS, especially with reference to the definition of what an indicator is.

The second challenge concerns PMS methods. While methodologies for data collection and data analysis are usually neglected by PMS studies (Choong, 2013), to compute social media metrics, it is necessary to develop IT and statistical competencies to download and analyse social media data. This challenge can serve as a basis to drive further research on the connection between IT, statistical and managerial competences when evaluating social media contributions.

From a practitioner perspective, this paper provides a set of operative options that can serve managers to evaluate the contribution of their social media activities. The proposed framework provides managers with a set of available metrics and methods to measure the contribution of social media activities from the identification of the type of social media contributions that need to be evaluated to the definition of the most appropriate metrics and the most suitable data collection and data analysis methodology. The traditional toolkit of organizational indicators is now enriched with new measures to quantify social media contributions. These measures differ from indicators traditionally adopted 
by organizations under different aspects. The first aspect concerns the timeliness of social media metrics, which is particularly high given that social media data are generated in real time. However, at the same time, this timeliness is ensured if appropriate methods for data collection and data analysis are endorsed, which often require advanced technical competencies on statistics and information technology. These requirements should be considered when selecting the person charged with evaluating social media. This person should not only have managerial competences but also mathematical and IT skills. This feature raises the issue about the organizational unit in charge of managing the social media, which is not obviously represented by the marketing area. On the contrary, a new role might appear inside organizations with ad hoc responsibilities for social media measurement.

The second aspect is related to the measurability of social media indicators, which is a weak point because some measures aim to quantify opinions and text. This introduces an element of subjectivity when selecting among the different available approaches for sentiment and content analysis. The third aspect is represented by the completeness of social media metrics, which is high only if several social media indicators are computed. To date, synthetic indicators to quantify, in a unique measure, social media contributions have not been found. On the contrary, several indicators exist, each of them focused on a specific aspect of social media. This finding suggests that if an overall view about social media contributions needs to be obtained, a measurement dashboard should be developed.

As a final point, we highlight the pace at which social media evolves, which makes it difficult to have an updated overview of both PMS metrics and methods. We have provided a framework based on theoretical contributions available until early 2016, which should undoubtedly be updated periodically. 


\section{References}

Agostino, D. (2013), “Using social media to engage citizens: a study of Italian municipalities”, Public Relations Review, Vol. 39 No.3, pp. 232-234.

Asur, S. and Huberman, B.A. (2010), "Predicting the future with social media”, in Proceedings of Web Intelligence and Intelligent Agent Technology (WI-IAT), IEEE/WIC/ACM International Conference, pp. $492-499$.

Atkinson, J., Salas, G. and Figuerao, A. (2015), “Improving opinion retrieval in social media by combining features-based coreferencing and memory-based learning”, Informatics Science, Vol. 299, pp. 20-31.

Bhardwaj, N., Shukla, A. and Swarnakar, P. (2014), "Users' Sentiment Analysis in Social Media Context using Natural Language Processing”, in Proceedings of The International Conference on Digital Information, Networking, and Wireless Communications (DINWC2014), pp. 103-111.

Bernabé-Moreno, J., Tejeda-Lorente, A., Porcel, C., Fujita and H., Herrera-Viedma, E. (2015), “CARESOME: A system to enrich marketing customers acquisition and retention campaigns using social media information”, Knowledge-Based Systems, Vol. 80, pp. 163-179.

Bonsón, E. and Ratkai, M. (2013), “A set of metrics to assess stakeholder engagement and social legitimacy on a corporate Facebook page”, Online Information Review, Vol. 37 No. 5 pp. 787 - 803.

Bravo-Marquez, F., Mendoza, M. and Poblete, B. (2014), “Meta-level sentiment models for big social data analysis”, Knowledge-Based Systems, Vol. 69, pp. 86-99.

Buckley, S., Ettl, M., Jain, P. Luss, R., Petrik, M., Ravi, R.K. and Venkatramani, C. (2014), “Social media and customer behavior analytics for personalized customer engagements”, IBM Journal of Research and Development, Vol.58 No.5/6, pp.7:1-7:12.

Bunescu, R. and Mooney, R. (2007), “Extracting Relations from Text: From Word Sequences to Dependency Paths”, in A. Kao and S.R. Poteet (Eds.), Natural Language Processing and Text Mining, Springer, pp.29-44. 
Canonico, P., De Vito, E., Esposito, V., Martinez, M., Mercurio, L., Pezzillo Iacono, M. (2015), The boundaries of a performance management system between learning and control, Measuring Business Excellence, Vol. 19 No. 3, pp. 7-21.

Chen, H., Chiang, R.H.L. and Storey, V.C. (2012), "Business Intelligence and data analytics: from big data to big impact”; MIS Quarterly, Vol. 36 No.4, pp.1165-1188.

Choi, S., Park, J. and Park, H.W. (2012), "Using social media data to explore communication processes within South Korean online innovation communities”, Scientometrics, Vol. 90, pp. 43-56.

Choong, K.K. (2013), “Understanding the features of performance measurement system: a literature review”, Measuring Business Excellence, Vol. 17 No. 4, pp. 102-121.

Crumpton, M.A. (2014), "Accounting for the cost of social media", The Bottom Line: Managing library finances, Vol. 27 No. 3, pp. $96-100$.

Coulter, K.S. and Roggeveen, A. (2012) "Like it or not: Consumer responses to word-of-mouth communication in on-line social networks”, Management Research Review, Vol. 35 No. 9, pp.878 889.

Diakopoulos, N., Naaman, M. and Kivran-Swaine, F. (2010), "Diamonds in the Rough: Social Media Visual Analytics for Journalistic Inquiry”, in IEEE Conference on Visual Analytics Science and Technology (IEEE VAST 2010), Salt Lake City, Utah, USA, 2010, pp. 115-122.

Duggan, M., Ellison, N.B., Lampe, C., Lenhart, A., and Madden, M. (2015), Social Media Update 2014, Pew Research Centre, available at http://www.pewinternet.org/2015/01/09/social-mediaupdate-2014/

Dzvapatsva, G.P., Mitrovic, Z. and Dietrich, A.D. (2014), "Use of social media platforms for improving academic performance at Further Education and Training colleges”, Journal of Information Management, Vol.16 No 1, pp.1-7.

Ellison, N.B. and Boyd, D. (2013), “Sociality through Social Network Sites”, in W.H. Dutton (Ed.), The Oxford Handbook of Internet Studies, Oxford: Oxford University Press, pp. 151-172.

El-Sayed H. and Westrup, C. (2011), “Adopting Enterprise Web 2.0 Collaborative Technologies in Business: The Implications for Management Accountants”, Research executive summary series, Vol. 7, No.4, July 2011, University of Manchester 
Farrugia, M., Hurley, N., Payne, D. and Quigley, A. (2012), “Social Network Construction in the Information Age: Views and Perspectives”, In I. Ting, T. Hong, \& L. Wang (Eds.), Social Network Mining, Analysis, and Research Trends: Techniques and Applications, Hershey, PA, pp. 131-155.

Ferrara, E., De Meo, P., Fiumara, G. and Baumgartner, R. (2014), "Web data extraction, applications and techniques: a survey”, Knowledge Based Systems, Vol. 70, pp. 301-323.

Fersini, E., Messina, E. and Pozzi, F.A. (2014), “Sentiment analysis: Bayesian Ensemble Learning”, Decision Support Systems, Vol. 68, pp.26-38.

Fisher, T. (2009), “ROI in social media: a look at the arguments”, Journal of Database Marketing \& Customer Strategy Management, Vol. 16, pp. 189 - 195.

George G, Haas M and Pentland AS (2014) Big data and management. Academy of Management Journal, Vol. 57 No. 2, pp. 321-326.

Hanna, R., Rohm, A. and Crittenden, V.L. (2011), “We're all connected: the power of the social media ecosystem”, Business Horizons, Vol. 54, pp. 265-273.

Herring, S.C. (2010), “Web Content Analysis: Expanding the Paradigm”, In Hunsinger, J., Allen, M. and Klastrup, L. (Eds.), International Handbook of Internet Research, Dordrecht: Springer, pp. 233-249

Hoffman, D. L. and Fodor, M. (2010), "Can You Measure the ROI of Your Social Media Marketing?”, MIT Sloan Management Review, Vol. 52 No.1, pp. 40-49.

Hu, X., Tang, J., Gao, H. and Liu, H. (2013), “Unsupervised Sentiment Analysis with Emotional Signals”, in Proceedings of the 22nd international conference on World Wide Web, pp. 607-618.

Jobs, Ch.G. and Gilfoil, D.M., (2014), “A social media advertising adoption model for reallocation of traditional advertising budgets”, Academy of Marketing Studies Journal, Vol. 18, No.1, pp. 235248.

Kaplan, A. and Haenlein, M. (2010), "Users of the world, unite! The challenges and opportunities of social media”, Business Horizons, Vol. 53 No. 1, pp. 59—68.

Kane, G.C., Alavi, M., Labianca, G. and Borgatti, S.B. (2014), “What’s Different about Social Media Networks? A Framework and Research Agenda”, MIS Quarterly, Vol. 38 No. 1, pp. 274304. 
Kaske, F., Kügler, M. and Smolnik, S. (2012), "Return on Investment in Social Media - Does the Hype Pay Off? Towards an Assessment of the Profitability of Social Media in Organizations”, in Proceedings of 45th Hawaii International Conference on System Sciences, pp. 3898-3907.

Khan, G.F., Hoffman, M.C. and Misztur, T., (2014), "Best Practices in Social Media at Public, Non-profit, Education, and Health Care Organizations”, Social Science Computer Review, Vol. 32(5), pp. 571-574.

Kim, Ch., Wegener, R. and Hoppe, F., (2014), “Media’s blockbuster business tool: Big Data”, The Business Times, available at http://www.businesstimes.com.sg/opinion/medias-blockbusterbusiness-tool-big-data .

Krippendorff, K. (1980). Content Analysis: An Introduction to Its Methodology. Newbury Park, CA: Sage.

Kwak, H. Lee, C., Park, H. and Moon, S. (2010), "What is Twitter, a social network or a news media?”, In Proceedings 19th International Conference on World Wide Web, ACM, Raleigh, North Carolina, USA, 2010, pp. 591-600.

Larson, K.M. and Watson, R.T. (2013), “The impact of Natural Language Processing-Based textual analysis of social media interactions on decision making”, ECIS 2013 Completed Research. Paper 70.

Li, J., Peng, W., Li, T., Sun, T., Li, Q. and Xu, J. (2014), “Social network user influence sensemaking and dynamics prediction”, Expert Systems with Applications, Vol. 41, pp. 5115-5124.

Marres, N. and Weltevrede, E. (2013), “Scraping the social? Issues in live social research”, Journal of Cultural Economy, Vol. 6 No.3, pp. 313-335.

Meekings, A., and Briault, S. (2013), “The “control tower” approach to optimising complex service delivery performance”, Measuring Business Excellence, Vol. 17. No.3, pp. 15-27.

McCaughey, D., Baumgardner, C., Gaudes, A., Larochelle, D., Wu, K.J., Raichura, T. (2014), “Best practices in Social Media”, Social Science Computer Review, Vol.32(5), pp.575-589.

Michaelidou, N., Siamagka, N.T. and Christoduulides, G. (2011), “Usage, barriers and measurement of social media marketing: An exploratory investigation of small and medium B2B brands”, Industrial Marketing Management, Vol. 40, pp. 1153-1159. 
Neely, A., Adams, C., and Crowe, P. (2001), “The performance prism in practice”; Measuring Business Excellence, Vol. 5 No.2, pp. 19-23.

Neri, F., Aliprandi, C., Capeci, F. and Quadros, M. (2012), “Sentiment Analysis on Social Media”, in Proceedings of the 2012 International Conference on Advances in Social Networks Analysis and Mining, pp. 919-926.

Ngai, E.W.T., Xiu, L. and Chau, D.C.K. (2009), “Application of data mining techniques in customer relationship management: A literature review and classification”, Expert Systems with Applications, Vol. 36 No. 2, pp.2592-2602.

Ngai, E.W.T., Taoa, S.S.C., Karen K.L. and Moon, K.K.L. (2015), “Social media research: Theories, constructs, and conceptual frameworks”, International Journal of Information Management, Vol. 35, pp. 33-44

Nguyen, T.T., Quan, T.T. and Phan, T.T. (2014), “Sentiment search: an emerging trend on social media monitoring systems”, Aslib Journal of Information Management, Vol. 66 No. 5 pp. 553 580.

Paltoglou, G. and Thelwall, M. (2012), “Twitter, MySpace, Digg: Unsupervised Sentiment Analysis in Social Media”, ACM Transactions on Intelligent Systems and Technology, Vol. 3 No. 4, pp.1-19.

Pang, B., and Lee, L. (2008), “Opinion mining and sentiment analysis”, Foundations and Trends in Information Retrieval, Vol. 1 No. 1-2, pp.1-135.

Peters, K., Chen, Y., Kaplan, A. M., Ognibeni, B. and Pauwels, K. (2013), “Social Media Metrics - A Framework and Guidelines for Managing Social Media”, Journal of Interactive Marketing, Vol. 27, pp. 281-298.

Pinkerton, B. (1994), "Finding what people want: Experiences with the WebCrawler”, In Proceedings of the 2nd International World Wide Web Conference (Chicago).

Powell, G.R., Groves, S.W. and Dimos,J. (2011), ROI of Social Media: How to improve the return on your social marketing investment, John Wiley \& Sons: New York.

Raybourn, E.M., (2014), “A new paradigm for serious games: Transmedia learning for more effective training and education”, Journal of Computational Science, Vol.5 No.3, pp.471-481. 
Romero, N.L. (2011), "ROI. Measuring the social media return on investment in a library”, The Bottom Line, Vol. 24 No.2, pp. 145-151.

SEC (2013), SEC Says Social Media OK for Company Announcements if Investors Are Alerted, Press Release, available at https://www.sec.gov/News/PressRelease/Detail/PressRelease/1365171513574 .

Sebate, F., Berbegal-Mirabent, J. Cañabate, A. and Lebherz, P.R., (2014), “Factors influencing popularity of branded content in Facebook fan pages”, European Management Journal, Vol.32 No.6, pp. 1001-1011.

Senior, J., (2015), “Creating value from Big Data through advanced customer analytics”, Bain \& Company.

Shet, A. and Nagarajan, M. (2009), “Semantics-Empowered Social Computing”, IEEE Internet Computing, Vol. 13 No. 1, pp.76-80.

Sheth, A., Thomas, C. and Mehra, P. (2010), “Continuous Semantics to Analyze Real-Time Data", IEEE Internet Computing, Vol.14 No. 6, pp. 84-89.

Sihm, K.L., and Koh, H.C. (2001), "Balanced scorecard: a rising trend in strategic performance measurement”, Measuring Business Excellence, Vol. 5 No. 2 pp. 18 - 27.

Snead, J.T. (2013), “Social media use in the U.S. Executive branch”, Government Information Quarterly, Vol. 30 No.1, pp. 56-63.

Sobkowicz, P., Kaschesky, M. and Bouchard, G. (2012), “Opinion mining in social media: Modeling, simulating, and forecasting political opinions in the web”, Government Information Quarterly, Vol. 24 No. 4, pp. 470-479.

Stemler, S. (2001), “An overview of content analysis”, Practical Assessment, Research \& Evaluation, Vol. 7 No. 17, available at http://pareonline.net/getvn.asp?v=7\&n=17 (accessed 19 December 2014).

Thelwall, M., Wilkinson, D. and Uppal, S. (2010), "Data Mining Emotion in Social Network Communication: Gender Differences in MySpace”, Journal of the American Society for Information Science and Technology, Vol. 61 No. 1, pp. 190-199.

van Dam, J.W. and van de Velden, M. (2015), “Online profiling and clustering of Facebook users”, Decision Support Systems, Vol. 70, pp. 60-72. 
Wan, X. (2011), "Bilingual co-training for sentiment classification of Chinese product reviews”, Computational Linguistics, Vol. 37 No. 3, pp. 587-616.

Waters, R.D., Burnett, E., Lamm, A. and Lucas, J. (2009), “Engaging stakeholders through social networking: How nonprofit organizations are using Facebook”, Public Relations Review, Vol. 35 No.2, pp. 102-106.

Xianghua, F., Guo, L., Yanyan, G. and Zhiqiang, W. (2013), "Multi-aspect sentiment analysis for Chinese online social reviews based on topic modeling and HowNet lexicon”, Knowledge Based Systems, Vol. 37, pp. 186-195.

Yan, G., He, W., Shen, J. and Tang, C. (2014), “A bilingual approach for conducting Chinese and English social media sentiment analysis”, Computer Networks, Vol. 75 Part B, pp. 491-503.

Zhang, Z., Li, X., and Chen, Y. (2012), “Deciphering word of mouth in social media: Text-based metrics of consumers reviews”, ACM Transactions on Management Information Systems, Vol.3 No.1, pp. 1-23. 
Annex 1 - List of PMS metrics with their reference formulas

\begin{tabular}{|c|c|c|c|}
\hline PMS metrics & References & $\begin{array}{l}\text { Detailed } \\
\text { measure }\end{array}$ & Main reference formula ${ }^{1}$ \\
\hline $\begin{array}{l}\text { Financial } \\
\text { indicators }\end{array}$ & $\begin{array}{l}\text { Fisher, 2009; Powell } \\
\text { et al., 2011; Romero, } \\
\text { 2011; Kaske et al., } \\
\text { 2012, Crumpton, } \\
\text { 2014; Jobs and Gilfoil, } \\
\text { 2014 }\end{array}$ & $\begin{array}{l}\text { Social media } \\
\text { ROI }\end{array}$ & $\frac{\text { profit from social media activities }}{\text { investments on social media activities }}$ \\
\hline \multirow{4}{*}{$\begin{array}{l}\text { Network } \\
\text { structure } \\
\text { indicators }\end{array}$} & \multirow{4}{*}{$\begin{array}{l}\text { Coulter and } \\
\text { Roggeveen, 2012; } \\
\text { Ellison and Boyd, } \\
\text { 2013; Kane et al., } \\
\text { 2014; Li et al., 2014; } \\
\text { Bernabé-Moreno et } \\
\text { al., } 2015\end{array}$} & Multiplexity & $\begin{array}{c}\text { number of exchanges per each relationship } \\
\text { between two nodes of the network } \\
\text { number of relationships between a generic node (i) } \\
\text { and other nodes in the network }\end{array}$ \\
\hline & & Density & $\frac{\text { actual connections between actors inside a network }}{\text { maximum number of potential connections }}$ \\
\hline & & Centrality & $\begin{array}{c}\text { number of shortest paths to connect two generic } \\
\text { nodes l and m passing from a reference node (i) } \\
\text { number of shortest paths to connect } \\
\text { two generic nodes }(\mathrm{l}) \text { and }(\mathrm{m})\end{array}$ \\
\hline & & Closeness & $\begin{array}{l}\frac{1}{\text { lenght of the shortest path between }} \\
\text { two generic nodes (i) and (l) }\end{array}$ \\
\hline \multirow{4}{*}{$\begin{array}{l}\text { Interaction } \\
\text { indicators }\end{array}$} & \multirow{4}{*}{$\begin{array}{l}\text { Hoffman and Fodor, } \\
\text { 2010; Agostino, 2013; } \\
\text { Bonsón and Ratkai, } \\
2013\end{array}$} & Awareness & $\frac{\text { total number of 'Likes'on a Facebook post }}{\text { total number of posts on Facebook }}$ \\
\hline & & Engagement & $\frac{\text { total number of comments on a Facebook posts }}{\text { total number of posts on a Facebook page }}$ \\
\hline & & Word of mouth & number of posts on Facebook wall \\
\hline & & Virality & $\frac{\text { total number of 'Shares'on Facebook }}{\text { total number of Facebook posts }}$ \\
\hline $\begin{array}{l}\text { Content } \\
\text { indicators }\end{array}$ & $\begin{array}{l}\text { Waters et al., 2009; } \\
\text { Diakopoulos et al., } \\
\text { 2010; Herring, } 2010\end{array}$ & Relevance & $\begin{array}{l}\text { term - vector space representation } \\
\text { of the SM message at a given minute of time } \\
\text { transcript for the minute when } \\
\text { the message occurred }\end{array}$ \\
\hline
\end{tabular}

\footnotetext{
${ }^{1}$ Several formulas often exist for the same measures. We have listed here the most common ones
} 


\begin{tabular}{|c|c|c|c|}
\hline & & Uniqueness & $\begin{array}{l}\text { term - vector space representation } \\
\text { of the SM message } \\
\text { centroid term - vector space representation } \\
\text { of all the SM messages } \\
\text { Where the 'term-vector space' is the graphical } \\
\text { representation on a diagram of a social media } \\
\text { message and SM stands for Social Media }\end{array}$ \\
\hline \multirow{3}{*}{$\begin{array}{l}\text { Sentiment } \\
\text { indicators }\end{array}$} & \multirow{3}{*}{$\begin{array}{l}\text { Asur and Huberman, } \\
\text { 2010; Zhang et al., } \\
2012\end{array}$} & $\begin{array}{l}\text { Subjectivity } \\
\text { ratio }\end{array}$ & $\begin{array}{c}\text { number of tweets with a } \\
\text { positive and negative sentiment } \\
\text { number of tweets with a neutral sentiment }\end{array}$ \\
\hline & & Polarity ratio & $\begin{array}{c}\text { number of tweets with a } \\
\text { positive sentiment } \\
\text { number of tweets with a } \\
\text { negative sentiment }\end{array}$ \\
\hline & & $\begin{array}{l}\text { Sentiment } \\
\text { divergent } \\
\text { metric }\end{array}$ & $\begin{array}{l}\begin{array}{l}\text { sentiment of post by customer (i) - } \\
\text { sentiment of post by customer }(\mathrm{l})\end{array} \\
\text { total number of investigated customer } \\
\text { Where the sentiment of the customer posts is } \\
\text { computed by making the average of the sentiment of } \\
\text { each word inside the text of the post }\end{array}$ \\
\hline
\end{tabular}

